\title{
Política Energética do II Plano Nacional de Desenvolvimento: teoria, resultados e reflexões ${ }^{1}$
}

\section{João Victor Machado}

Mestrando no Programa de Pós-graduação em Ciências Econômicas, IE-UNICAMP (2018)

Email: joao.vmachado.economia@gmail.com

\section{Resumo:}

O presente artigo tem por objetivo analisar, a partir de uma leitura de política industrial como estratégia de desenvolvimento, as perspectivas e os resultados da Política Energética do II Plano Nacional de Desenvolvimento, especificamente, avaliar se há evidências para afirmar que o plano transformou a estrutura energética do país. Do ponto de vista metodológico, procura-se primeiro discutir os fundamentos teóricos que norteiam a implementação desse tipo de política, e posteriormente, resgatar o quadro energético do período durante e após a implementação do plano, avaliando quais foram às respostas orientadas pelo Estado sobre a estrutura produtiva. Os resultados indicam mudança da estrutura energética, com queda da dependência em relação ao petróleo e aumento da participação das hidrelétricas na geração de energia.

Palavras-chave: Política Industrial; II Plano Nacional de Desenvolvimento; Política energética.

\section{Abstract:}

The objective of this article is to analyze, from a reading of industrial policy as a development strategy, the perspective and results of the Energy Policy of the II National Development Plan, specifically to evaluate if there is evidence to affirm that the plan transformed the structure the country. From a methodological point of view, it is firstly sought to discuss the theoretical foundations that guide the implementation of this type of policy, the energy picture of the period during and after the implementation of the plan, evaluating which were the responses oriented by the State on the productive structure. The results indicate a change in the energy structure, with a drop in dependence of petroleum and an increase of the hydroelectric power participation in the energy generation.

Key words: Industrial Policy; II National Development Plan; Energy policy. JEL Code: L52, 014, Q48.

\footnotetext{
${ }^{1}$ Artigo desenvolvido com o apoio da Coordenação de Aperfeiçoamento de Pessoal de Nível Superior (CAPES).
} 


\section{INTRODUÇÃO}

O desenvolvimentismo nacional e a intervenção estatal são características que marcaram a industrialização brasileira entre o pós-guerra e o final dos anos 1970. O movimento político e econômico pró-política industrial teve dois momentos de maior destaque ao longo dessa fase: durante o Plano de Metas de Kubitschek, e durante o regime militar, com a elaboração do II Plano Nacional de Desenvolvimento (II PND) (SUZIGAN \& FURTADO, 2006). A pesquisa busca estudar um setor específico desse segundo projeto.

O presente artigo tem por objetivo analisar, a partir de uma leitura de Política Industrial (PI) como estratégia de desenvolvimento, as perspectivas e os resultados da Política Energética do II PND, especificamente, avaliar se há evidências para afirmar que o plano transformou a estrutura energética do país. Não se trata de estudar o processo de industrialização em si, mas de avaliar o papel do Estado como protagonista da transformação na estrutura energética do país.

Do ponto de vista metodológico, procura-se primeiro discutir os fundamentos teóricos que norteiam a implementação desse tipo de política, e posteriormente resgatar o quadro energético do período durante e após a implementação do plano, avaliando quais foram às respostas orientadas pelo Estado sobre a estrutura produtiva.

A Política Energética do II PND, proposta para investimentos de longo prazo, estava orientada na direção de reduzir a dependência do país em relação às fontes externas de energia. Para isso, o governo apostava na diversificação e substituição do petróleo por outras fontes, especialmente, geração de energia a partir de hidroelétricas.

A literatura se divide ao se posicionar sobre política industrial e também sobre o diagnóstico feito para a elaboração do II PND. Enquanto para a teoria neoclássica, a atuação do Estado, assim como a política industrial seria meramente reativa e restrita, para a visão neoschumpteriana-evolucionária a intervenção do Estado deveria ser ativa e abrangente, articulando políticas para setores que possam contribuir, através da mudança tecnológica e institucional, para o ganho de competitividade da economia.

O trabalho está estruturado em 4 seções além desta introdução. A seção 2 discute os fundamentos teóricos que norteiam a defesa da política industrial como estratégia de desenvolvimento. A seção 3 apresenta uma revisão breve da literatura sobre o II PND, e os pontos principais da Política Energética do plano. Na seção 4 é feita uma leitura dos principais indicadores do cenário energético, durante e após a elaboração do plano. Na seção 4 são feitas algumas considerações finais, e por fim, estão as referências bibliográficas.

\section{POLÍTICA INDUSTRIAL: FUNDAMENTOS TEÓRICOS}

Essa seção busca desenvolver alguns aspectos gerais relacionados a política industrial, tais como seu escopo e definição, questão macro, problemas e elementos sobre o arcabouço institucional, para que seja possível estabelecer o embasamento teórico por trás da elaboração e implementação de uma política industrial como estratégia de desenvolvimento. 
p. 41 - Política Energética do II Plano Nacional de Desenvolvimento: teoria, resultados e reflexões

\subsection{Escopo e Definição}

A própria definição do termo "is not a trivial task" (SUZIGAN \& VILLELA, 1997, p. 15), pois não faz parte de um consenso dentro da literatura e abrange a contribuição de vários autores. Suzigan e Villela (1997) separam as definições pelo escopo da política industrial, classificando as contribuições dos autores em dois grupos, com pontos de vista opostos. O primeiro entende política industrial em um sentido estrito, já o segundo grupo entende política industrial em um sentido mais amplo, abrangendo outras medidas que afetam o desempenho industrial (SUZIGAN \& VILLELA, 1997).

Por um lado, as medidas de política industrial podem ser caracterizadas por políticas direcionadas para indústrias específicas, como é o caso da defesa feita por Chang (1994), por outro, a partir de medidas horizontais que afetam o desempenho industrial como um todo. Essa leitura é balizada pela diferença de fundamentos analíticos em que os autores se baseiam, assim como as influências que permeiam as diversas escolas do pensamento.

Para a teoria neoclássica, a atuação do Estado, assim como a política industrial seria meramente reativa e restrita, isto é, direcionada apenas para corrigir as falhas de mercado, como externalidades, informação assimétrica, incerteza etc. Parte-se do pressuposto de que a economia encontra-se numa trajetória de equilíbrio subótimo, onde os agentes são compelidos pelo comportamento maximizador, com estruturas industriais dadas. Nessa perspectiva as intervenções se justificariam apenas nos casos em que seus benefícios não fossem menores do que os possíveis problemas que poderiam advir com a atuação estatal, como falhas de governo, problemas de informação e de rentseeking (SUZIGAN \& FURTADO, 2006).

Já para a visão neoschumpteriana-evolucionária a intervenção do Estado deveria ser ativa e abrangente, articulando políticas para setores que possam contribuir, através da mudança tecnológica e institucional, para o ganho de competitividade da economia. Essa última interpretação concilia a visão Schumpteriana, onde a inovação e as novas combinações desempenham um papel crucial no desenvolvimento econômico, com o arcabouço teórico da economia evolucionária, na qual acredita que o processo de mudança da economia capitalista se assemelha a um processo evolucionário biológico. Nessa perspectiva descartam-se os pressupostos de equilíbrio e racionalidade substantiva de agente com comportamento maximizador, e defende-se que há uma coevolução te tecnologias, de estruturas de empresas e de indústrias (SUZIGAN \& FURTADO, 2006).

Acredita-se que essa segunda abordagem consiga maior profundidade para explicar um mundo dinâmico e com mudanças tecnológicas. Outra questão importante no conjunto de definições está relacionada com os mecanismos de coordenação. Em modelos de competição perfeita, como disposto pela teoria neoclássica, não é necessário uma coordenação ex-ante, indo além, medidas de política industrial interviriam apenas como uma forma de coordenação ex-post, isto é, seriam empregadas como resposta para corrigir as falhas de mercado - conceito que é inclusive criticado por Cimoli et at (2007) 
devido ao seu uso genérico para sinalizar o debate ${ }^{2}$. Em contraposição, a política industrial é vista, sobretudo, como um mecanismo de coordenação ex-ante para a teoria neoschumpteriana-evolucionária (SUZIGAN \& FURTADO, 2006).

A definição que orienta o trabalho foi desenvolvida por Chang (1994, p. 60): “We propose to define industrial policy as a policy aimed at particular industries (and firms as their components) to achieve the outcomes that are perceived by state to be efficient for the economy as a whole". Essa definição está de acordo com uma política industrial seletiva, e requer o cuidado com quatro elementos críticos. O primeiro está relacionado com a preocupação em designar a política industrial a indústrias específicas, o que elimina a opção por políticas para a indústria como um todo, o segundo que a eficiência deve ser um pilar fundamental dos propósitos que orientam a política industrial, o terceiro está relacionado com "for the economy as a whole", isto é, seus efeitos não podem permanecer concentrados em setores específicos, devem manifestar-se na economia como um todo. O último elemento enfatiza o fato da leitura pelo Estado do que será eficiente para a economia de forma geral, o que não significa que será um diagnóstico factível para todos (CHANG, 1994).

\subsection{Questão macroeconômica, possiveis problemas e organização institucional}

Tópicos importantes do arcabouço macroeconômico estão em consonância com a agenda de política industrial, tais como, o progresso da distribuição de renda, uma provisão eficiente de bens públicos como infraestrutura, ambiente educacional e proteção ambiental, assim como atividades antitrustes (CHANG, 1994). Nessa lógica, a articulação entre macroeconomia e política industrial é fundamental e também recíproca:

On the one hand, macroeconomic policy affects industrial policy by determining relative prices (tradables-nontradables) throught the exchange rate, by influencing the level of investments via interest rate, and by signalling macroeconomic stability and the state's fiscal capcacity for implementing incentive policies and investing in infrastructure, science and technology, and educacion. On the other hand, a successful industrial policy strategy may help macroeconomic policy by increasing productivi efficiency and total factor productivity in the economy (SUZIGAN \& VILLELA, 1997, p. 26).

Sabe-se que uma estratégia de desenvolvimento pautada em política industrial pode ser afetada pela política macroeconômica, a partir de políticas de câmbio e juros,

\footnotetext{
2 "O problema suscitado por tal esquema não é o das "falhas de mercado" serem irrelevantes. Ao contrário: o problema está em que dificilmente uma situação empírica qualquer apresentará alguma semelhança significativa com tal "padrão de medida" - por exemplo, em termos de plenitude do mercado, de perfeição da concorrência, dos conhecimentos possuídos pelos agentes econômicos, da imutabilidade das tecnologias e preferências, da 'racionalidade' da tomada de decisões, etc (CIMOLI et al, 2007, p. 58)
} 
p. 43 - Política Energética do II Plano Nacional de Desenvolvimento: teoria, resultados e reflexões

entretanto, a política industrial pode, por outro lado, amparar o desempenho da política macroeconômica, como por exemplo, através dos aumentos de produtividade. 0 importante é que a PI seja praticável e seu alcance não seja limitado, para isso, é fundamental a estabilidade do ambiente macroeconômico.

Além da sintonia entre PI e política macroeconômica, o sucesso da primeira como estratégia de desenvolvimento está ligado a três requisitos principais. O primeiro a sua capacidade de articulação com instrumentos, normas e regulamentações como: sistemas de proteção, financiamento, promoção das exportações, incentivos fiscais, defesa da concorrência, patentes etc. O segundo é coordenar o avanço da infraestrutura com o progresso da política industrial, isto é, abrigar a infraestrutura como variável de políticas. E terceiro, é necessária a organização institucional, nessa lógica, instituições públicas, as quais são instituições executoras, devem compartilhar perspectivas, objetivos e resultados com as empresas, que são as entidades representativas (SUZIGAN \& FURTADO, 2006).

A força da PI como estratégia de desenvolvimento não pode ser extenuada por possíveis problemas, como apontado pela escola mainstream, tais como: (i) Problemas de informação, insuficiente e assimétrica; (ii) Problemas de Rent-Seeking; (iii) Problemas Políticos, como problemas de legitimidade e controle democrático e (iv) Problemas de suporte institucional. Pois, o combate a esses problemas, que não são características exclusivas ao Estado, podem operar no sentido da própria capacitação e fortalecimento do mesmo, isto é, o Estado pode se capacitar em reduzir as assimetrias de informação, é capaz de desenvolver mecanismos de controle burocrático para se proteger contra o rent-seeking e os problemas políticos, e tem os instrumentos necessários para adequar e formatar um arcabouço institucional básico, definindo instâncias deliberativas e decisórias (CHANG, 1994). Além do mais, é preciso enxergar esses problemas não como barreiras intransponíveis, mas como dificuldades que emergem em qualquer quadro político; é imperativo avançar nas soluções e não paralisar o debate (RODRIK, 2007).

Sobre a questão do arcabouço institucional, Cimoli et al (2007) destaca duas maneiras complementares de se colocar a análise das instituições e políticas que orientam o desenvolvimento industrial. Por um lado, ressalta-se que historicamente não houve processo de desenvolvimento sem um conjunto básico de instituições complementares, normas de comportamento compartilhadas e políticas públicas. Por outro, há razões teóricas sólidas que fundamentam a defesa das instituições como um elemento fundamental no processo de mudança econômica.

Nessa perspectiva o papel dos mercados não se restringe a sua eficiência alocativa, mas também como ambientes que possam incentivar a entrada de novos produtos, técnicas de produção e formas de organização. Ganha destaca nessa leitura "como a arquitetura institucional organiza as interações entre os agentes e as maneiras como as políticas regulam os comportamentos e as formas da concorrência" (CIMOLI et al, 2007, p. 61). 


\section{II PLANO NACIONAL DE DESENVOLVIMENTO: ASPECTOS GERAIS E REVISÃO DOS AUTORES}

\subsection{PND: Interpretações}

O período que antecede o lançamento do II PND (1969-1973) denominado de "milagre econômico" foi marcado por um crescimento econômico vigoroso, que atingiu em média 11,4\% ao ano. De forma resumida, pode-se afirmar que esse crescimento foi facilitado pela utilização da capacidade ociosa do período anterior e de condições amplamente favoráveis no cenário internacional. A principal característica do crescimento no período foi a alavancagem oriunda do setor de bens de consumo duráveis, que expandiu, em média, em 22,9\% ao ano. Entretanto, devido ao descompasso entre o setor de duráveis e o setor de bens intermediários, houve um aumento vigoroso nas importações de determinados insumos básicos como petróleo, químicos e diversos metais, pressionando o balanço de pagamentos.

Durante a década de 1970 a economia mundial assiste ao esgotamento do ciclo de prosperidade conduzido sobre a ordem de Bretton Woods. Esse cenário é marcado pelo enfraquecimento do nível de atividade das principais economias industrializadas, pela perda do fôlego do comércio mundial e pelo avanço da inflação, em concomitância com o aumento das taxas de juros. No início da década ocorre a suspensão da conversibilidade do dólar em ouro e a progressiva flutuação das taxas de câmbio com efeitos diversos sobre os países subdesenvolvidos (CARNEIRO, 2002).

Dois fatos afetaram diretamente os países subdesenvolvidos nesse período: as bruscas elevações do preço do petróleo e o forte aumento das taxas de juros. Em relação ao primeiro ponto, os preços do petróleo se deslocam do patamar de U\$ 3 o barril para aproximadamente U\$12 o barril em 1974, caracterizando o Primeiro Choque do Petróleo. Entre esse último ano e 1978 os preços gravitam em torno de U\$ 12 a U\$ 15, para voltar a disparar no Segundo Choque do Petróleo após 1979. O preço da matéria atinge o pico em 1981, ao patamar de U\$ 37 o barril. Dado que o petróleo representava a principal fonte de geração de energia na época, a quadruplicação dos preços constitui um golpe incisivo sobre os países periféricos não produtores, significando a deterioração dos termos de troca e o declínio dos fluxos de comércio (CARNEIRO, 2002).

Se a extrapolação da tendência da conta corrente do balanço de pagamentos, sob a hipótese de manutenção dos termos de troca aos níveis favoráveis dos primeiros anos da década de 1970, já indicava significativos desequilíbrios, o choque do petróleo agravou drasticamente essa tendência. Oitenta por cento do consumo deste produto no Brasil era importado. As possibilidades de substituição de importações de petróleo e outros insumos no curto prazo eram obviamente muito limitadas (BATISTA, 1987, p. 68).

É nesse cenário que o Estado aumenta ainda mais sua influência sobre os rumos do desenvolvimento industrial (SUZIGAN, 1988). Nessa lógica opta por preservar o nível 
p. 45 - Política Energética do II Plano Nacional de Desenvolvimento: teoria, resultados e reflexões

de crescimento e ampliar a diversificação da estrutura produtiva, elementos consubstanciados II PND implementado nesse mesmo ano. O plano consistia em um programa de investimentos em diversas áreas, com o objetivo de transformar a estrutura produtiva, e concomitantemente, superar os desequilíbrios externos, a fim de colocar o Brasil na condição de potência emergente. O governo elegeu como setores prioritários o setor de insumos básicos, o setor energético e o de bens de capital (BASTISTA, 1987). O governo apostava na transformação da matriz energética e de transportes, perseguindo o objetivo de "cobrir a fronteira entre o subdesenvolvimento e o desenvolvimento" (II PND, 1974, p. 7).

A resposta brasileira à crise através do II PND fomentou críticas e o debate. Carneiro (2002) identifica pelo menos três correntes de interpretação sobre o período: uma visão ortodoxa, na qual entende que a estratégia adotada representou uma evasão ao ajustamento; uma interpretação estruturalista, segundo a qual classifica o período como de ajustamento estrutural; e uma terceira vertente denominada de visão crítica, que enfatiza a inadequação e o fracasso do ajustamento estrutural.

Na primeira ótica se encaixa a contribuição dada por Malan \& Bonelli (1983). Segundo os autores o período representou um retardamento do ajuste às novas condições internacionais, o que tornou a economia brasileira mais exposta a choques externos. A elevação do preço do petróleo e a deterioração dos termos de troca afetaram a balança de pagamentos, criando déficits significativos na balança comercial. Por outro lado, as elevações das taxas de juros internacionais implicavam no aumento dos encargos da dívida, expandindo o déficit em transações correntes. Nesse cenário, três alternativas se colocavam: retrair a demanda doméstica através de um ajuste recessivo clássico; expandi-la à custa de um endividamento maior; ou comprimir o consumo em favor do investimento (CARNEIRO, 2002). Ao optar pela segunda alternativa, o governo inclinavase a manter os níveis de crescimento, arcando com o prejuízo de retardar o ajustamento, lembrando que o sentido estratégico dessa alternativa estava na legitimação do regime militar.

Ao contrario dessa visão, para Castro \& Souza (1985) a política de 1974 não significava postergar os problemas vigentes na economia brasileira, as soluções é que ficariam adiadas, dado o longo prazo de maturidade dos grandes investimentos. Para os autores a "estratégia de 1974" representou uma profunda transformação na estrutura produtiva, uma opção por superar conjuntamente a crise e o subdesenvolvimento. Segundo os autores a racionalidade do plano estava em: "tentar sustentar a conjuntura impedindo uma descontinuidade de consequências imprevisíveis; assegurar o espaço necessário para absorção do surto anterior de investimentos; e é claro, modificar, a longo prazo, a estrutura produtiva (CASTRO E SOUZA, 1985, p. 37)". O protagonismo do programa ficou por conta das empresas estatais: Eletrobrás, Siderbrás, Embratel, dentre outras empresas públicas, as quais foram destinatárias da grande massa de investimentos previstas no plano. Em suma, a estratégia reprimia a reversão cíclica, permitindo a manutenção acelerada das taxas de crescimento até o final da década. O que há de condenável no período para os autores, não foram as diretrizes econômicas estabelecidas com o II PND, e sim, o regime político vigente (CASTRO \& SOUZA, 1985). 
Em uma visão crítica do II PND Lessa (1977) afirma que entre 1974 e 1975 o plano transcorreu em consonância com as metas pré-estabelecidas, com fortalecimento do BNDES, direcionamento dos recursos pelo Conselho de Desenvolvimento Industrial para áreas prioritárias, entre outras medidas, no espírito de converter em realidade a proposta do plano. Entretanto, já em 1975 há uma desaceleração do processo de crescimento e o fracasso já se apresenta em 1977, com a retração dos programas de investimento. 0 autor busca explicação para o fracasso do II PND através dos movimentos cíclicos. Como a economia tinha apresentado durante cerca de 8 anos uma taxa de crescimento de $10 \%$ ao ano, uma expansão industrial vigorosa apoiada na indústria de bens duráveis, com um aumento na taxa de investimento de $16 \%$ em 1968, para $27 \%$ ao ano em 1974 , e multiplicado por cinco as suas importações, a economia brasileira tinha atingido um estágio de sobreacumulação. Sendo assim a grande "performance" anterior do milagre já indicava a provável e medíocre ou mesmo cinzenta "performance" subsequente (LESSA, 1977; 1982).

Soma-se a essa posição a contribuição de Tavares e Lessa (1983). Os autores direcionam três críticas principais para o período 1974-1980: extrema utilização de financiamento externo, sobredimensionamento dos projetos e elevada relação de capital-produto dos novos investimentos, exigindo um alto crescimento da taxa de poupança. Serra (1982) se apoia nessa visão crítica para colocar dois problemas centrais: sobre o momento inadequado em que ocorreu o lançamento do plano, devido ao cenário de conjuntura internacional recessiva e reversão do crescimento da economia doméstica, e o segundo em relação ao sobredimensionamento dos projetos, como também afirma Batista (1987, p. 69) "algumas das metas estabelecidas mostraram-se claramente irrealistas".

Em suma, o plano encontrava obstáculos desde o seu lançamento. Partindo de um visível sobredimensionamento dos projetos, utilizando-se em larga escala de empréstimos externos e carecendo de articulação entre os investimentos. A manutenção do crescimento acelerado se colocava com custos crescentes, e perspectivas questionáveis. No plano de fundo, o programa de investimentos buscava satisfazer o conjunto de interesses dos militares, na busca da legitimação do regime vigente.

A próxima seção busca descrever quais eram as metas para a política energética, para tentar esclarecer qual era a leitura do governo sobre as condições vigentes e quais eram suas perspectivas para o setor.

\subsection{Política Energética do /I PND}

O estabelecimento de metas é certamente o aspecto mais polêmico da PI e alvo predileto dos críticos dessa política. Mas é vital numa estratégia industrial impulsionada pela inovação e norteada por transformações tecnológicas e mudanças estruturais de empresas e indústrias (SUZIGAN \& FURTADO, 2006, pp. 166). 
p. 47 - Política Energética do II Plano Nacional de Desenvolvimento: teoria, resultados e reflexões

O tema que envolvia a dependência em relação ao petróleo e suficiência energética já havia sido problematizado em tempos anteriores. Desde o Plano de Metas postulava-se investimentos em áreas básicas como siderurgia e refino do petróleo por parte do Estado, dado a insuficiência do ânimo empresarial (LESSA, 1983).

Durante o lançamento do plano o governo tinha expectativas expressivas para a economia brasileira, como, atingir mil dólares de renda per capita em 1979. Resgatando as metas estabelecidas pelo II PND pode-se perceber a atenção despendida com o problema da energia. Entre as tarefas para atingir os objetivos, como consolidar uma indústria moderna, o plano previa também ajustar a estrutura econômica à situação de escassez do petróleo. "Tal mudança implica em grande ênfase nas indústrias básicas, notadamente o setor de Bens de Capital e o de Eletrônica pesada, assim como o campo dos insumos básicos, a fim de substituir importações e, se possível, abrir novas frentes de exportação" (II PND, 1974, p. 8).

A Política de Energia figura como uma peça fundamental dentro da estratégia nacional. O plano reconhecia que o Brasil dependia em grande escala do petróleo para transporte, e matéria-prima para indústria química. No total de energia consumida no país o petróleo e gás respondiam por $48 \%$. Segundo o projeto do II PND o Brasil importava cerca de $40 \%$ das suas fontes de energia.

Para adequar a política energética à opção de manter o ritmo de crescimento acelerado, dado que um aumento da oferta de energia no curto prazo era inviável, era preciso diminuir a dependência do petróleo, substituindo, quando possível, por eletricidade e carvão e reduzir sua parcela importada.

No longo prazo, deve o Brasil prover internamente suas fontes básicas de energia. Uma estratégia nesse sentido levará pelo menos uma década, e dependerá essencialmente dos resultados da prospecção de petróleo, da exploração do xisto, da descoberta de significativas jazidas de urânio e da melhor solução que a tecnologia mundial encontrar para a principal nova forma de energia, em substituição do petróleo (II PNDE, 1974, p. 74).

Para alcançar esses objetivos o plano elencava cinco elementos principais, com metas precisas:

(i) Reduzir a dependência em relação às fontes externas de energia.

A primeira linha de ação nesse aspecto atuaria no sentido de aumentar a oferta interna de petróleo. Para isso seria destinado um programa maciço de prospecção e produção com investimentos que passariam de $\mathrm{Cr} \$ 8$ bilhões (1970-74) para cerca de $\mathrm{Cr} \$$ 26 bilhões no quinquênio de vigência do plano, o que representava um aumento de $225 \%$ em termos nominais. No total a perspectiva de investimentos para o petróleo estava em $\mathrm{cr} \$ 56$ bilhões. Conjuntamente estava o desenvolvimento do programa do xisto, com investimentos da PETROBRAS em torno de $\mathrm{Cr} \$ 2,8$ bilhões no setor, orientados inclusive para o financiamento da primeira usina industrial. 
Uma segunda linha de ação envolvia a diversificação das fontes internas de energia e a substituição do petróleo por outras fontes. Para isso estava determinado: um avanço no Programa de Eletrificação das Ferrovias; uma política que buscava transferir o transporte de massa para setores ferroviário, marítimo e fluvial; execução do Programa Nacional de Transportes coletivos, para uma substituição gradual do automóvel, e ampliação do uso do carvão para fins industriais.

Uma terceira linha de ação se orientava em reduzir a demanda de petróleo. Para isso, o regime apostava em uma política realista nos preços de derivados de petróleo, com forte aumento no preço da gasolina; medidas para evitar o desperdício ou onerar seu uso supérfluo, e adoção de tecnologias poupadoras de energia. O regime contava também com medidas sobre o comércio internacional, colocando tetos aos dispêndios com importação de petróleo no balanço de pagamentos.

(ii) Emprego intensivo de energia de origem hidroelétrica na produção de bens altamente intensivos em energia, aproveitando as vantagens do país na geração de energia hidráulica e permitindo o avanço da substituição das importações de petróleo.

(iii) Execução do Programa Ampliado de Energia Elétrica. Estava previsto uma cifra de $\mathrm{Cr} \$ 200$ bilhões em investimentos no setor, o que proporcionaria um aumento de $60 \%$ na capacidade instalada de geração. O programa incluía as usinas de Itaipu além do fortalecimento de uma central nuclear no país.

(iv) Programa de Carvão. Estava pautado em pesquisas para viabilizar uso generalizado na indústria.

(v) Desenvolvimento de Programa de pesquisas de Fontes Não Convencionais de Energia, baseado na economia do hidrogênio e solar.

(vi) Produção de minerais energéticos nucleares, com a sistematização de pesquisas e a instalação de usinas.

Essas foram as metas e perspectivas que estavam previstas na Política de Energia do II PND. É possível perceber a preocupação em adaptar a estrutura produtiva ao novo cenário internacional, na tentativa de diminuir a dependência em relação ao petróleo e desenvolver fontes alternativas de geração de energia.

\section{ANÁLISE DOS INDICADORES E O BALAÇO ENERGÉTICO}

Essa seção busca fazer um levantamento dos principais indicadores do setor energético durante e após a implantação do II PND, na tentativa de fundamentar o debate e investigar qual o quadro que ficou após a vigência do plano.

\subsection{Investimentos: perspectivas e realizações para o setor}

Grande parte dos investimentos no setor energético estava voltada para adaptar a economia brasileira a condição de escassez de petróleo no mercado internacional. Cabe lembrar também que essa inclinação estava de acordo com o diagnóstico realizado na preparação do plano. Ao aumentar a capacidade de produção de insumos básicos e 
p. 49 - Política Energética do II Plano Nacional de Desenvolvimento: teoria, resultados e reflexões

petróleo, ampliava-se consequentemente a oferta de bens internacionais (tradables), visando à substituição das importações e à promoção das exportações, o que atacaria no longo prazo o problema da balança de pagamentos (BATISTA, 1987).

Para isso os investimentos estavam programados em aumentar a oferta interna de petróleo e incentivar o uso intensivo de fontes alternativas na geração de energia, especialmente de origem hidroelétrica. Deve-se ressaltar que grande parcela dessas inversões seria de longa maturação.

Tabela 1: Investimentos como porcentagem da Formação Bruta de Capital Fixo (FBCF) em (\%), 1970-1979

Projeções

do II PND

\begin{tabular}{lllllllll}
\hline & $1970 / 74$ & 1975 & 1976 & 1977 & 1978 & 1979 & $1975 / 79$ & $1975 / 79$ \\
\hline Petróleo & 1,1 & 1,2 & 1,4 & 1,6 & 1,9 & 2,3 & 1,7 & 2,0 \\
Carvão e Gás & - & & - & - & - & - & - & 2,4 \\
Eletricidade & 7,3 & 7,1 & 7,7 & 8,6 & 9,3 & 9,2 & 8,4 & 15,0 \\
\hline
\end{tabular}

Fonte: Batista (1987)

Ao analisar a tabela 1 é possível observar que os investimentos em petróleo dobraram em relação à formação bruta de capital fixo durante 1974/79, sendo a cifra mais próxima em relação às estimativas do plano. Houve um aumento da participação dos investimentos em eletricidade na FBCF de 7,3\% em 1974 para 9,2\% em 1979, com efeitos positivos no setor, ficando ainda muito aquém da estimativa extraordinária que era esperada de $15 \%$ de participação. Há evidências para afirmar que o caso do Carvão e Gás, enquadra-se nos fracassos em termos de estimativas e investimentos que não foram realizados. Por outro lado, Batista (1987) apresenta uma crítica relacionada aos investimentos realizados e que não apresentaram resultados. O autor estima que cerca de US\$ 15 bilhões (preços de 1985) foram aplicados em projetos sem estimativas de retorno, tais como A Ferrovia do Aço, o Programa Nuclear, a AÇOMINAS, a Caraíba Metais, a ALCANORTE entre outras, indicando que uma parte da dívida externa brasileira foi desperdiçada em investimentos sem resultados. Entretanto, o autor conclui que, se analisado a FBCF como um todo, que somou US\$ 428 bilhões entre 1974 e 1979, a contribuição dos investimentos sem retorno é diminuta.

\subsection{Conjecturas do Petróleo}

O primeiro tópico do programa energético se preocupava em reduzir a dependência em relação às fontes externas de energia. Para isso o regime se propunha a aumentar a oferta interna de petróleo, diversificar as fontes internas de energia e reduzir a demanda de petróleo. Abaixo um balanço energético. 
A produção de energia a partir do petróleo fica estagnada durante todo o período de vigência do II PND (1974-1979), mesmo com o aumento das inversões (Tabela 1), passando a aumentar potencialmente apenas no início da década de 1980, assim como a extração de petróleo bruto. Podem-se apontar dois fatores para explicar esse comportamento. Primeiro, as reservas conhecidas em terra já estavam em um nível crítico de exaustão. Segundo, apesar das descobertas offshore, o prazo de maturação entre a descoberta e o início da produção obedece a um prazo mínimo (BATISTA, 1987). Sendo assim há evidências para afirmar que o crescimento vertiginoso da produção e exploração de petróleo na década de 1980 responderam aos investimentos realizados anteriormente, durante o II PND.

Gráfico 1: Extração e Produção de Petróleo, 1974- 1987

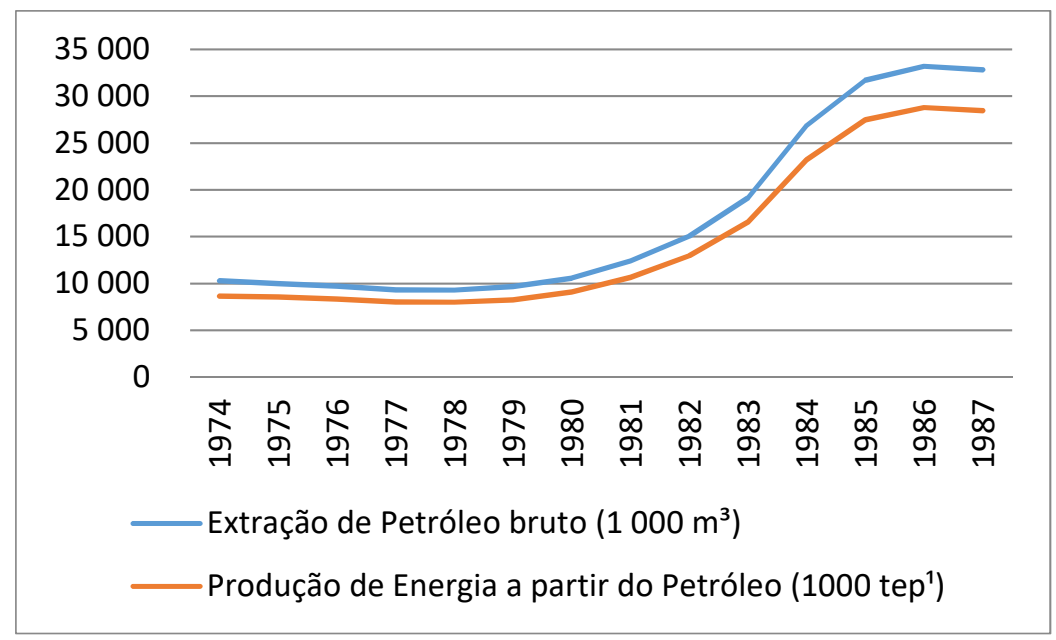

Fonte: Elaborado pelo autor a partir das Estatísticas do século XX (IBGE./ (1) Toneladas Equivalentes de Petróleo.

Em relação a diversificação das fontes internas de energia, após 10 anos do lançamento do plano foi reduzida a oferta oriunda do petróleo, de cerca de $40 \%$ do total para 30\% do total. Essa diminuição contrasta com o aumento da oferta de energia a partir de fontes renováveis. A participação hidráulica na geração de energia passa de $19 \%$ em 1974 para 31\% 10 anos depois. O mesmo ocorre para a geração a partir dos produtos da cana de açúcar que aumentam de $5 \%$ para $10 \%$ do total da oferta de energia primária gerada. Já a oferta interna a partir de urânio não ocorre durante todo o decorrer do II PND. 
p. 51 - Política Energética do II Plano Nacional de Desenvolvimento: teoria, resultados e reflexões

Gráfico 2: Participação na Oferta interna de Energia, segundo as fontes de energia em 1974

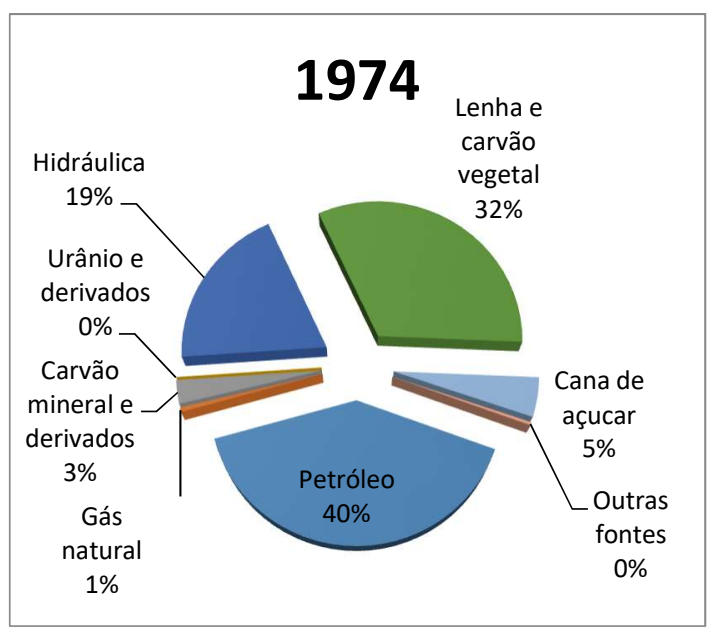

Fonte: Elaborado pelo autor a partir das Estatísticas do século XX (IBGE).
Gráfico 3: participação na Oferta Interna de Energia, segundo as fontes de energia em 1984

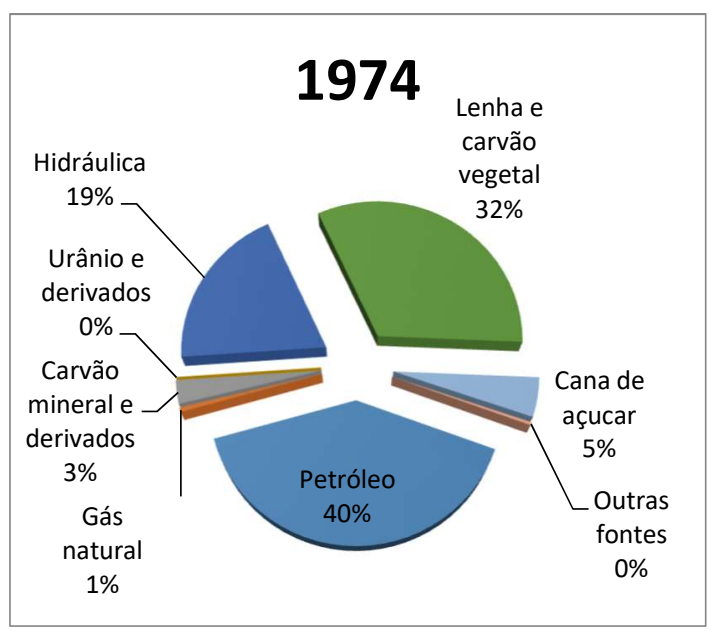

Fonte: Elaborado pelo autor a partir das Estatísticas do século XX (IBGE).

Durante o período do "milagre econômico" a economia brasileira apresentou taxas aceleradas de crescimento industrial, liderada pelos bens de consumo duráveis. Esse período foi marcado também pelo aumento da dependência estrutural da economia brasileira em relação ao petróleo. A participação do hidrocarboneto no consumo primário total de energia saltou de 34\% em 1971 para 40\% em 1973. O consumo aparente de petróleo cresce continuamente no período, já as importações do insumo elevam-se de 59\% do consumo interno para 81\% (GIAMBIAGI, 2011). Esse era o cenário no momento de preparação e lançamento do II PND.

Analisando o período 1974-1979 percebe-se que a taxa de dependência estrutural do petróleo permanece estável, cuja participação no consumo primário total fica em torno de 40\%. O consumo aparente de petróleo mantém a trajetória de crescimento do período anterior, saindo de 47 milhões de $\mathrm{m}^{3}$ em 1974, para cerca de 67 milhões de $\mathrm{m}^{3}$ em 1979. As importações no mesmo período passam de $80 \%$ do consumo interno em 1974 para de $85 \%$ em 1979. O aumento das importações no período resulta da resposta lenta da produção, em relação aos investimentos, em concomitância com o aumento do consumo interno. 
Gráfico 4: Importação, Consumo aparente e Dependência Estrutural do Petróleo, 19741987

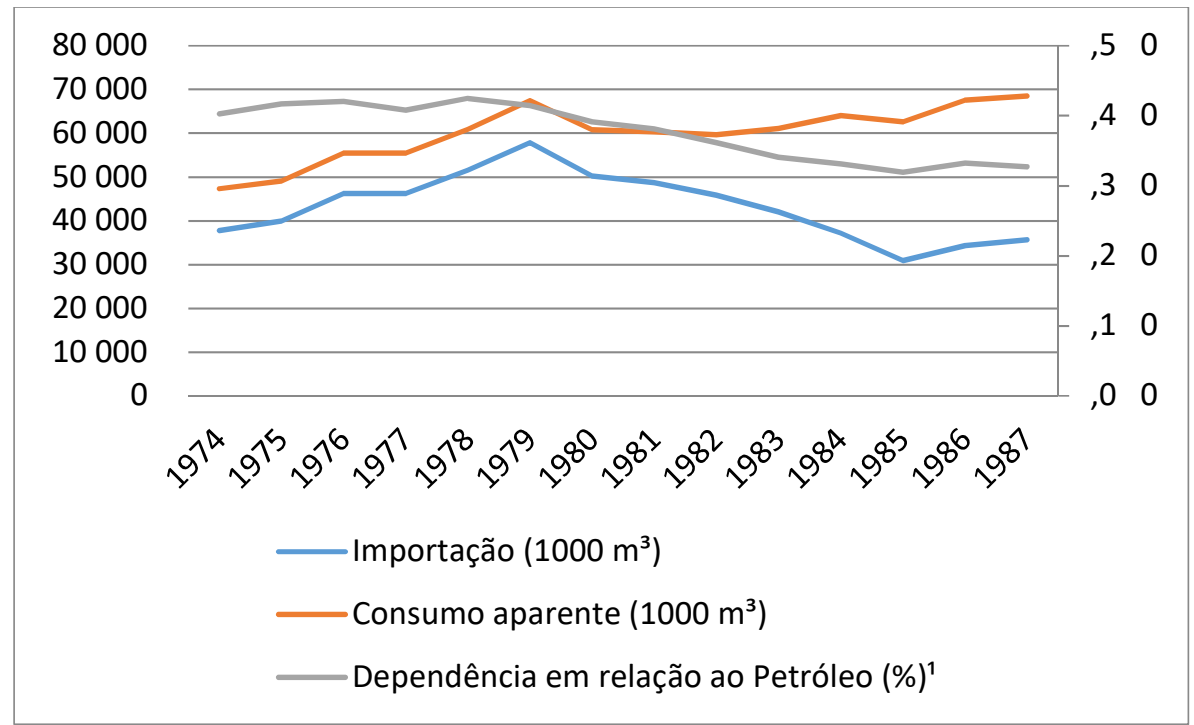

Fonte: Elaborado pelo autor a partir das Estatísticas do Século XX (IBGE). ${ }^{1}$ Consumo de energia a partir do petróleo em relação ao consumo total de energia primária.

Após o Segundo Choque do Petróleo em 1979 ocorre uma inflexão desses indicadores. A dependência estrutural expressa uma trajetória de queda durante quase toda a década de 1980, cuja participação no consumo interno declina de 41\% em 1979 para 33\% em 1987. As importações despencam, em média, de 58 milhões de $m^{3}$ em 1974 para 35 milhões de $\mathrm{m}^{3}$ em 1987. A participação das importações no consumo interno cai para $52 \%$ no mesmo ano. Esses indicadores coincidem com o aumento da produção que ocorre na mesma fase.

Esses indicadores contrastam com o progresso do setor de energia elétrica. A programação de investimentos em energia elétrica, especialmente ao que se refere às hidroelétricas visava aumentar o potencial de competitividade, dado que o Brasil possuía vantagens comparativas no setor. Ao estimular a utilização intensiva da geração de energia através das hidroelétricas, o governo perseguia o objetivo de transformar a matriz energética do país, o que corresponderia à substituição "estrutural" das importações. A estratégia estava montada para diminuir a participação do petróleo importado e aumentar a parcela das hidroelétricas na geração de energia. Esse fenômeno também estava ligado à eletrificação das ferrovias dos metrôs e também a eletrificação rural (BATISTA, 1987). Abaixo alguns indicadores do setor. 
p. 53 - Política Energética do II Plano Nacional de Desenvolvimento: teoria, resultados e reflexões

Tabela 2: Indicadores sobre a geração de energia elétrica

\begin{tabular}{|c|c|c|c|c|c|c|c|}
\hline \multirow{3}{*}{ ANOS } & \multicolumn{7}{|c|}{ ENERGIA ELÉTRICA (GWh) } \\
\hline & \multirow{2}{*}{$\begin{array}{c}\text { Potência } \\
\text { instalada das } \\
\text { usinas (MW) }\end{array}$} & \multicolumn{3}{|c|}{ Produção (1) } & \multicolumn{3}{|c|}{ Consumo (1) } \\
\hline & & Total & Hidráulica & Térmica & Total & Industrial & $\begin{array}{c}\text { Não } \\
\text { industrial }\end{array}$ \\
\hline 1974 & 17526 & 71469 & 65595 & 5874 & 58741 & 31674 & 27067 \\
\hline 1975 & 19056 & 76954 & 72093 & 4861 & 66013 & 35616 & 30397 \\
\hline 1976 & 20827 & 88016 & 82809 & 5207 & 75267 & 41748 & 33519 \\
\hline 1977 & 22491 & 97820 & 92748 & 5072 & 83989 & 46526 & 37463 \\
\hline 1978 & 25300 & 108914 & 101595 & 7319 & 93699 & 52438 & 41261 \\
\hline 1979 & 27970 & 121401 & 115262 & 6139 & 104825 & 58791 & 46034 \\
\hline 1980 & 31147 & 133767 & 129011 & 4756 & 115874 & 64287 & 51587 \\
\hline 1981 & 35734 & 136258 & 129225 & 7033 & 119710 & 64303 & 55407 \\
\hline 1982 & 38989 & 150602 & 142372 & 8230 & 132115 & 72914 & 59201 \\
\hline 1983 & 39584 & 161969 & 151475 & 10494 & 141415 & 77150 & 64265 \\
\hline 1984 & 41568 & 172269 & 161969 & 10300 & 157128 & 89068 & 68060 \\
\hline 1985 & 45085 & 195917 & 181170 & 14747 & 173073 & 98603 & 74470 \\
\hline 1986 & 45908 & 221144 & 202465 & 18679 & 186373 & 106696 & 79677 \\
\hline 1987 & 50329 & 219025 & 202538 & 16487 & 192127 & 107391 & 84736 \\
\hline
\end{tabular}

Fonte: Adaptado Estatísticas do Século XX (IBGE). (1) Inclusive concessionários e autoprodutores.

Através dos investimentos programados no setor, em consonância com o Programa Ampliado de Energia Elétrica o governo previa aumentar em $60 \%$ sua capacidade de geração. A tabela 5 indica que a produção total de energia elétrica aumentou de forma continua durante todo o período. Entre 1974/79 o aumento foi de cerca de $70 \%$. Em relação a produção hidráulica o aumento foi de $75 \%$ no mesmo período, com o consumo industrial aumentando sua participação de $54 \%$ para $56 \%$ no consumo total de energia elétrica.

O aumento da produção representou também a ampliação na participação no consumo interno de energia primária. Em 1974 a participação hidráulica no total do consumo de energia era de 19\%, saltando para 31\% em 1984. Esse parâmetro indica que a economia brasileira durante e a pós a vigência do II PND se orientou no sentido de aumentar a dependência em relação às hidroelétricas no consumo total de energia primária, disposição que fazia parte do conjunto de interesses do governo, e das estimativas do II PND.

\subsection{Resumo dos resultados}

A partir do diagnóstico desenvolvido na seção anterior é possível estabelecer os seguintes pontos críticos relevantes: 
a) Houve aumento na participação dos investimentos em Petróleo em relação à FBCF durante 1974-79, entretanto, devido a longa maturação dos investimentos, o aumento da produção e exploração de petróleo ocorreu apenas no início da década de 1980.

b) Mesmo com o aumento absoluto, a participação do petróleo na oferta total de energia primária caiu de 40\% em 1974 para 30\% 10 anos depois.

c) A medida de dependência estrutural em relação ao petróleo se manteve entre 197479 e passou a reduzir continuamente na década de 1980.

d) A importação de petróleo aumentou entre 1974-79, passando a reduzir após o Segundo Choque de Petróleo de 1979.

e) A média dos investimentos em eletricidade em relação a FBCF aumentou de 7,3\% (1970/74) para 8,3\% (1974/79), ficando aquém do esperado de (15\%).

f) A participação hidráulica na oferta total de energia saltou de 19\% em 1974 para 31\% em 1984.

g) Mesmo sem toda a materialização dos investimentos no setor, a produção de energia elétrica ganhou espaço no setor energético. Houve ampliação da produção e um pequeno aumento da participação de consumo de energia elétrica industrial no consumo total.

\section{CONSIDERAÇÕES FINAIS}

O presente artigo teve por objetivo analisar, a partir de uma leitura de política industrial como estratégia de desenvolvimento, as perspectivas e os resultados da Política Energética do II PND, especificamente, avaliar se há evidências para afirmar que o plano transformou a estrutura energética do país. Não se trata de estudar o processo de industrialização em si, mas de avaliar o papel do Estado como protagonista da transformação na estrutura energética do país.

O diagnóstico revela indícios para afirmar que o II PND foi responsável por promover uma mudança positiva da estrutura energética. Por um lado, após a maturação dos investimentos no setor de petróleo, houve aumento da produção e exploração da matéria, assim como a redução da dependência estrutural em relação ao petróleo. Por outro lado, houve o aumento da participação hidráulica na oferta total de energia, resultados que já estavam previstos pelo governo após a maturação dos investimentos do II PND.

Esses resultados corroboram a hipótese de que a articulação da Política Industrial pelo Estado foi importante para consolidar o processo de industrialização da economia brasileira, e como estudado aqui, teve influência na transformação da estrutura energética do país.

Como o trabalho se limitou a investigar as políticas e o setor energético, não é possível se posicionar sobre a efetividade do diagnóstico e dos resultados obtidos do plano como um todo. Dito de outra forma, a pesquisa não procurou subestimar os custos 
p. 55 - Política Energética do II Plano Nacional de Desenvolvimento: teoria, resultados e reflexões

com os erros de política econômica que foram cometidos, tais como o sobredimensionamento dos projetos, a utilização demasiada de financiamento externo e a manutenção de taxas aceleradas de crescimento com a reversão da conjuntura internacional e doméstica. Também não se pretendeu aqui, um estudo exaustivo de todos os setores industriais, o que pode ser objeto para trabalhos futuros.

\section{REFERÊNCIAS BIBLIOGRÁFICAS}

BATISTA, J. C. A. A estratégia de ajustamento externo do Segundo Plano Nacional de Desenvolvimento. Revista de Economia Política.São Paulo, v.7, n.2, 1987.

CARNEIRO, R. M.. Desenvolvimento em crise: a economia brasileira no ultimo quarto do século XX. São Paulo, SP; Campinas, SP: Editora UNESP: UNICAMP/IE, 2002.

CASTRO, A. B. A economia brasileira em marcha forçada. Coautoria de Francisco Eduardo Pires de Souza. 2. ed. Rio de Janeiro, RJ: Paz e Terra, 1985.

CHANG, H.-J. The Political Economy of Industrial Policy. London: Macmillan, 1994.

CIMOLI, M.; DOSI, G.; NELSON. R. R.; STIGLITZ J. Instituições e políticas moldando o desenvolvimento industrial: uma nota introdutória. Revista Brasileira de Inovação, Rio de Janeiro, vol. 6 (1), jan.-jun. 2007

GIAMBIAGI, Fabio et al. (Org.). Economia brasileira contemporânea: (1945-2010). 2. ed. Rio de Janeiro, RJ: Elsevier: Campus, 2011

IBGE. Estatísticas históricas do Brasil: séries econômicas, demográficas e sociais de 1550 a 1988. Disponível em < https://seculoxx.ibge.gov.br/economicas/tabelassetoriais/energia.html>. Acesso em: 02 jan. 2018.

II PND. Segundo Plano Nacional de Desenvolvimento. Brasília. set. 1974.

LESSA, C. “Visão Crítica do II PND”. In: Revista Tibiriça no 6, jan/mar, 1977.

Quinze Anos de Política Econômica. SP, Ed. Brasiliense, 1982

MALAN, P., BONELLI, R. Crescimento econômico, industrialização e balanço de pagamentos: o Brasil dos anos 1970 aos anos 1980. Rio de Janeiro: Ipea/Inpes, Nov. 1983. (Texto para discussão, n. 60).

RODRIK, D. Normalizing industrial policy. September 2007

SERRA, J. Ciclos e mudanças estruturais na economia brasileira do pós-guerra. In: BELLUZZO, L. G. M., COUTINHO, R.(Org). Desenvolvimento capitalista no Brasil: ensaios sobre a crise. São Paulo: Brasiliense, v.1., 1982.

SUZIGAN, W. Estado e Industrialização do Brasil. Revista de Economia Política, vol. 8, no. 4, pp. 5-16 out-dez/1988.

Elementos essenciais da política industrial. In: ALBUQUERQUE, E. Metamorfoses do capitalismo e processos de catch-up. Belo Horizonte: UFMG, 2017.

SUZIGAN, W. E FURTADO, J. Política Industrial e Desenvolvimento. Revista de Economia Política, vol. 26, no. 2 (102), pp. 163-185 abril-junho/2006. 
SUZIGAN, W.; VILLELA, A.V. Industrial Policy in Brazil. Campinas: Instituto de Economia/UNICAMP, 1997.

TAVARES, M. C., LESSA, C. Desenvolvimento industrial nos anos 1970: impasses e alternativas. Rio de Janeiro. IE/UFRJ, 1983. 